\title{
El ajuar de las iglesias kirishitan: interculturalidad y construcción de una identidad cristiana
}

Rie ARIMURA

Palabras clave: expansión ibérica, misiones católicas, Japón moderno temprano, ajuar de las iglesias, arte kirishitan

La mundialización del arte católico impulsada por la política expansionista de las monarquías ibéricas y la Iglesia católica en la primera era moderna se ha concebido tradicionalmente como una simple y rápida expansión de la civilización europea o una interacción bilateral entre el mundo ibérico y una determinada región. Así, se ha entendido también la cultura namban, definida como un fenómeno producido mediante el contacto directo entre ibéricos y japoneses durante los siglos XVI-XVII. Gracias a recientes avances en la investigación, sin embargo, se han empezado a reconocer las contribuciones de las organizaciones socioeconómicas nativas, además de conceder mayor relevancia a las interacciones producidas entre tradiciones culturales de diversas regiones no europeas como influyentes factores de alcance global. Los estudios de Impey, Jörg y Hidaka señalan, por ejemplo, que los motivos ornamentales de la laca namban presentan en mayor medida la influencia del arte islámico e hindú —en especial, guyaratí de India— más que la del arte chino y coreano (Impey y Jörg 2005: 77-81; Hidaka 2008: 6061). Respecto al atril japonés, se ha indicado que su estructura plegable muestra una clara influencia del atril para colocar el Corán (Yamazaki 2001: 30), aunque a esta consideración cabe añadir que dicha solución estructural se observa también en los atriles católicos producidos en la India, por lo que Japón pudo haber recibido la influencia estructural del atril islámico a través 
de los objetos procedentes de la India.

Por otra parte, gracias a las aportaciones de la tecnología y a aproximaciones interdisciplinarias, se ha comenzado a reexaminar los ejemplos del arte namban con nuevos criterios metodológicos. Ello ha permitido observar las interacciones artísticas presentadas no sólo en el aspecto formal-iconográfico, sino también en los materiales y técnicas de las obras. Tal es el caso de la campana de bronce Santiago que pertenece al Taketa Historical Museum (竹田市立歴史資料館), en Oita. Un análisis realizado recientemente sobre la composición química ha mostrado que el plomo empleado en dicha obra es probablemente una mezcla de plomo japonés y tailandés. De ello se pueden deducir complejas rutas de intercambios materiales de la época. Además, dicha campana pudo haber sido acuñada en Japón ("Taketa-shi no Santiago no kane” 2012: 21).

En el marco de esta revisión e innovación interpretativa, el presente trabajo trata de corroborar la interculturalidad manifestada en el ajuar litúrgico de las iglesias japonesas por medio de sacar a la luz nuevas referencias de la documentación occidental. Al respecto, cabe puntualizar que la ornamentación católica utilizada en el contexto japonés aparece referida en los manuscritos en diferentes ocasiones: por una parte, en forma de inventario de bienes; por otra parte, cuando se describen los espacios del culto católico o los traslados de objetos.

La primera parte de este trabajo se aproximará a las condiciones de la sociedad local en las que se introdujeron, circularon, ostentaron y protegieron los objetos de uso litúrgico-devocional. Por lo que señalan los documentos, el espacio del culto católico en Japón se caracterizó por su aspecto efímero. El ajuar de las iglesias tuvo un carácter provisional e incluso estuvo en constante movimiento. Ello fue la causa de que se perdieran muchas obras. Pero también esta dinámica de traslado de los ornamentos hizo enriquecer las manifestaciones visuales católicas: por una parte, creó un fenómeno de yuxtaposición o integración de objetos de distintas procedencias en diversos espacios sagrados; por otra parte, las obras traídas de distintas regiones del orbe marcaron la pauta para las producciones del arte católico en Japón, lo que impulsó el surgimiento de singulares expresiones artísticas. En la segunda 
parte de este ensayo se recopilarán las referencias documentales relativas a la adaptación y aculturación del ajuar eclesiástico. Se examinará también la recepción que hubo por parte de los nativos ante ornamentos nunca antes vistos. Finalmente, veremos cómo la conformación de un escenario litúrgico intercultural sirvió para construir y mostrar visualmente la identidad católica en la sociedad japonesa. Con ello, se revisarán los calificativos "a modo de iglesia" o "a modo de Europa" o "no nosso modo", que se mencionan en las fuentes.

\section{Dinámica de movilidad del ornamento católico en el contexto local}

La gran movilidad de recursos fue uno de los aspectos más notables de la expansión de la Iglesia católica dada a partir del siglo XVI. El intercambio de objetos fue una constante de los proyectos misionales: ello ayudó a que se creara un nuevo sistema de producción y comercio estableciendo una especialización de los productos que cada sitio o región tenía que proveer para satisfacer las demandas internas y externas. El Japón no fue una excepción de ello y en la siguiente noticia relativa a los franciscanos se ejemplifica el tráfico de objetos provocado por las misiones en el Japón:

...que la provincia [de San Gregorio de Filipinas] fuesse obligada a remitir a Japón vino, y cera para las missas, sayal para los religiosos, botica para los enfermos; y de allá se traería harina para hostias, y algunas cosas curiosas para los altares (Martínez 1756: 165).

El traslado de la ornamentación eclesiástica fue una práctica realizada en diversas partes del mundo como resultado de los intercambios de hechuras artísticas entre las regiones lejanas y también con la finalidad de reutilizar las obras. ${ }^{1)}$ Empero, en el contexto japonés, la movilidad de los bienes adquirió mayor singularidad, ya que no sólo los materiales constructivos para edificar las iglesias y sus dependencias, como ejemplifica la iglesia dominica de Kyodomari, en Satsuma, que fue desarmada en 1609 debido a la política anticristiana y transportada a Nagasaki dividiendo los recursos constructivos en tres barcos, sino también el ajuar interior se mudaron de forma constante. 
La frecuencia con la que se llevó a cabo el traslado del ajuar interior no tuvo parangón. Además, en muchas ocasiones, la mudanza del ornato eclesiástico se realizó de manera completa porque a causa de los motines o persecuciones los misioneros se vieron obligados a salvar sus bienes en la medida que les fuera posible. Así, transportaron no sólo libros como breviarios y misales, sino también imágenes, frontales, retablos portátiles y "otros aderezos de altar" -que podían incluir cáliz, candelero, custodia, relicario, cruz- a los castillos fortificados de los kirishitan daimyo o casas de los fieles (BRAH, Cortes, 9/2663, f. 46r). Así, por ejemplo, el día de la Ascensión del año 1573, ante la amenaza de que Nobunaga, por fuerza de armas, podría desposeer al shogun Ashikaga Yoshiaki del estado, quemar la ciudad de Kyoto y despojar de las piezas de valor, Fróis intentó salvar los bienes de la iglesia dividiéndolos y enviándolos a distintas partes y así, “...embie con dos xpianos algunos lios con los ornamentos y libros a las sierras de Daigo a donde Sixto tiene parientes y otro poco de hato [ornato] a Xabata lugar de Fachima..." (BRAH, Cortes, 9/2663, f. 45v). Por otra parte, cuando no había tiempo de enviar los ornamentos, se los enterraba en el predio de la iglesia, tal y como hicieron con "la piedra del ara, ${ }^{2}$ y vn frasco de vino de las Missas" en la iglesia de Kyoto en 1573 (BRAH, Cortes, 9/2663, f. 78r-78v).

De igual modo, la documentación dilucida en qué manera se oficiaba la misa mientras el ajuar de la iglesia estaba bajo la custodia de los kirishitan daimyo en su castillo. Para sustituir la carencia de ornamentos, hubo casos en los que se recurrió a fieles nativos para pintar imágenes en papel (BRAH, Cortes, 9/2663, f. 86v). Al respecto, cabe agregar que el uso de papel como soporte de la pintura católica no fue únicamente una solución aplicada en casos improvisados como el anterior, pues en la ornamentación de las iglesias japonesas hubo una verdadera adaptación de las técnicas, materiales y motivos de la pintura japonesa.

Empero, ante la amenaza de revueltas y cuando no se podrían llevar los ajuares de la iglesia a sitios seguros se mandaba a soldados cristianos que protegieran el templo a fin de que éste mismo sirviera de almacén para cuidar los objetos religiosos de los fieles (BRAH, Cortes, 9/2663, f. 88r-88v). También cabe advertir que el transporte de la ornamentación conllevaba el 
peligro de ser víctima de robos y saqueos. Así sucedió a los jesuitas que se hallaban en Azuchi en 1582. Después de que Nobunaga muriera a causa de la conspiración planeada por su súbdito Akechi Mitsuhide, conocida como el Incidente de Honno-ji, se dieron perturbaciones en la región de "Cami" (Kami 上) porque había amenaza de que Akechi iría a alborotar la ciudad de Azuchi y el castillo de Nobunaga. Los jesuitas intentaron llevar en barco los ornamentos y plata de la iglesia a un sitio seguro. No obstante, los miembros de la embarcación resultaron ser ladrones y llegados al puerto comenzaron a robar los objetos. Por fortuna los padres pudieron salvar sus vidas gracias a la llegada de otra embarcación enviada por un cristiano, criado de Akechi (BRAH, Cortes, 9/2663, f. 301r).

El motivo del traslado de la ornamentación no estribó solamente en los disturbios político-sociales, sino también en las persecuciones cristianas. De hecho, antes de que Hideyoshi promulgara el edicto de expulsión de los bateren (1587) para todos los señoríos, las resistencias contra el cristianismo ya se habían manifestado de manera violenta a nivel regional. Así, en el señorío de Bungo, Tawara Chikataka (田原親賢, m. 1600), quien fue identificado como "Chicacata" en la documentación occidental y era hermano de la ex esposa del famoso kirishitan daimyo Otomo Sorin, mostró una postura claramente anticristiana. Los motivos para ello fueron diversos. En primer lugar, la actitud de Sorin de obligar a sus vasallos a destruir los templos sintoístas y budistas provocó el descontento entre los samurai del mismo señorío y aún más en Chikataka, quien pertenecía al linaje sacerdotal del santuario sintoísta de Nada (Nada hachimangu 奈多八幡宮) en Bungo. En segundo lugar, Sorin se divorció de su hermana, quien era conocida como “Madame Nada" (Nada fujin 奈多夫人, m. 1587), debido a la postura anticristiana de Chikataka y se casó con una cortesana cristiana que trabajaba para su hermana. Por último, Chikataka no teniendo hijo propio, adoptó a un niño del clan Yanagiwara (柳原), familia aristocrática de Kyoto. No obstante, este hijo adoptivo Tawara Chikatora (田原親虎) se bautizó a escondidas con el nombre de Simón. La profunda devoción cristiana de su hijo provocó la ira de Chikataka, quien lo expulsó del clan Tawara (BRAH, Cortes, 9/2663, ff. 132r138v). A causa de estos disgustos personales, Chikataka lanzó una 
persecución contra los cristianos, buscando destruir la iglesia y matar a los padres. Ante esta amenaza, los misioneros intentaron escaparse y salvar sus bienes, i.e. varios objetos de plata como cálices, custodia, relicarios (BRAH, Cortes, 9/2663, f. 139r; ARSI, Jap. Sin. 50, f. 30v).

Asimismo, la carencia de los objetos litúrgicos y devocionales también fue motivo de que el ajuar eclesiástico estuviese en constante mudanza. Por citar un ejemplo, después de celebrar la navidad de 1570 en la iglesia de la isla de Goto, en Nagasaki, el padre Alexandre Valeregio, S.J. quiso oficiar misa también en otras poblaciones de la misma comarca. Así, primero decidió mandar la ornamentación de la iglesia de Goto a "Vochica", que era una aldea ubicada a dos leguas de aquella localidad. Para ello, el padre solicitó a los cristianos de Vochica que "...me embiasen vna enbarcacion para que se llevassen los ornamentos, la qual ellos embiaron a otro dia, y juntamente cabalgaduras para que fuesemos por tierra..." (BRAH, Cortes, 9/2663, f. 4r4v). De Vochica dicho jesuita continuó su viaje con fines litúrgicos. La documentación indica que lo que viajaba junto con el padre no era sólo la ornamentación, sino también el grupo de coristas. En la población llamada "Pungama”, se acomodó la casa del capitán “...donde estava vna sala bien aparejada, y entoldada, a modo de iglesia, para q se hiziese en ella el Baptismo, con los ornamentos y aparejos de $n^{\text {ra }}$ iglesia, los quales yo avia embiado delante..." (BRAH, Cortes, 9/2663, f. 8r).

La práctica de transportar las piezas litúrgicas para el oficio de la misa no fue exclusiva del círculo de la Compañía de Jesús. Así, por ejemplo, cuando Juan Pobre, O.F.M. visitó Hirado, en Nagasaki el año de 1584:

Vino dos vezes de Firando a nangasaqui por tierras a ciertos negocios que le importavan, acontecio que tornando de la segunda vez de Nangasaqui para Firando por tierra avia de hazer la mayor parte del camino por tierra de gentiles, y todo su hato [ornato] que hera vn tintero de caña quebrado y un candelero de varro viejo y vnas disciplinas y linsas y agujas para remendarse cabria en la copa de vn sombrero (BRAH, Cortes, 9/2663, f. 406r). 
De aquí se deduce que el ornato que portaba Juan Pobre contrasta con las piezas de plata u otros objetos de valor que poseían los jesuitas. La circulación y uso de objetos de diferentes calidades es un aspecto importante para la comprensión de la cultura material católica. El arte como lenguaje visual servía de instrumento para demostrar el poder e identidad de la Iglesia. Para este fin, las piezas de alta calidad jugaron un papel importante. Por otro lado, a partir de esta noticia cabe suponer que los mendicantes en Japón, quienes aplicaron el sistema de "visita" para evangelizar en las aldeas, debieron llevarse consigo durante dichas visitas las piezas litúrgicas necesarias, tal y como hizo Juan Pobre.

\section{Adaptación y aculturación del ajuar eclesiástico}

Ahora bien, ¿qué clases de ornamentación se utilizaron en los espacios del culto kirishitan? Al respecto, cabe afirmar que el ajuar de las iglesias japonesas se diversificó según las circunstancias políticas e históricas del contexto local. En términos generales, antes de que se aplicara la política anticristiana se utilizaron piezas litúrgicas e imágenes importadas, al mismo tiempo que se difundieron hechuras japonesas que presentaban en mayor medida una aculturación formal-iconográfica, mientras que en la época de persecución se produjeron y veneraron las imágenes que se asemejaban a la iconografía budista, tal y como muestra María Kannon o Guanyin (Bodhisattva de compasión).

Desde los albores de la misión católica, coexistieron dos posturas opuestas: adaptación y aculturación tanto en la liturgia como en el ajuar eclesiástico. En la etapa primitiva, para conformar el espacio del culto, los misioneros introdujeron sólo imágenes devocionales, retablos portátiles y piezas litúrgicas adaptando la arquitectura nativa y altares existentes. Así, Francisco Xavier trajo consigo una imagen de Nuestra Señora e improvisó espacios del culto colocando la imagen o retablo encima del altar (BRAH, Jesuitas, leg. 9/7238, ff. 39v-41r). De igual modo, la iglesia fundada dentro del castillo de Ichiki en Satsuma en el tiempo de Francisco Xavier era así: "Nesta fortaleza fizeram os christãos huma igreia muito devota e bem ornada, em que tem hum retavolo da visitaçam..." (BRAH, Jesuitas, leg. 9/7238, f. 
41v). No obstante, con el transcurso del tiempo, llegaron a crear un escenario litúrgico muy distinto de las tradiciones budistas y sintoístas. El ajuar de la iglesia de la isla de Goto utilizado en la navidad del año 1570, por ejemplo, se describe de la manera siguiente:

...teniamos $\mathrm{n}^{\text {ra }}$ iglesia estaba muy bien adereçada, a la qual concurrieron todos los xpianos assi de la ciudad, como de las aldeas de la comarca... [...] ...vino el Rey desta isla con dos gentiles criados suyos, y espantado del ornato de la iglesia, dixo q en toda su vida, no avia visto semejante cosa, no acabando de alabarlo... [...] El día del nacimiento iban y venian gentiles a ver la iglesia, y marabillavanse mucho assi del hornato de el Altar, como de la armadura de la iglesia. Los xpianos los combidaban con vino de Arroz, conforme a la costumbre de Japon, y viendo los gentiles, la conformidad y amor de los xpianos, dezian q veian el paraiso, en la isla del Gotho (BRAH, Cortes, 9/2663, f. 4r).

La expresión: “...espantando del ornato de la iglesia, dixo q en toda su vida, no avia visto semejante cosa..." conduce a pensar que los misioneros debieron adornar el interior del templo de manera muy distinta a la tradición local. Pero ¿cómo era concretamente el ajuar eclesiástico de Japón?

En el documento antes citado de 1570, en el que se describe el viaje que Valeregio realizó para celebrar misa en diferentes poblaciones de la región de Goto, se hace mención del aprovechamiento de la casa del capitán como espacio litúrgico, es decir, “...estava vna sala bien aparejada, y entoldada, a modo de iglesia..." (Cortes, 9/2663, f. 8r). "Estar entoldada" podría significar al menos dos cosas distintas. Por una parte, el uso de toldaduras dentro del recinto sagrado formaba parte de la tradición budista, puesto que arriba de la imagen de Buda se colgaba una toldadura (buttengai 仏天蓋) hecha de madera que imitaba la cortina, mientras que dentro del espacio católico de Japón, "estar entoldada" podría referise al dosel que acompañaba la imagen sagrada colocada en el altar mayor. De hecho, este ornamento formaba parte del ajuar eclesiástico japonés desde tiempos de Francisco Xavier, ya que éste usaba "huma imagem de Nossa $S^{\text {nora }}$ da Anunçiação, e hum frontal com seu docel 
tudo de seda" (BRAH, Jesuitas, leg. 9/7238, ff. 39v, 42r) para conformar el espacio del culto. La forma del dosel podría variar según el caso, ya que en la escena de la misa representada en el Biombo namban de Kano Naizen, en la parte superior del cuadro de Salvator Mundi se presenta un paño bermejo, en tanto que en una capilla representada en los paneles izquierdos del mismo biombo, una pintura de Salvator Mundi estaba flanqueada por cortinas bermejas y de brocado (Figura 1). Por otra parte, Fernão Guerreiro, S.J. (ca. 1550-1617) apunta que la iglesia estaba adornada con papeles que cubrían el techo (López 1970: 30). De lo anterior surge la posibilidad de que "estar entoldada" se refiriese también a los papeles que ornamentaban el techo.

Vale la pena mencionar que la cortina fue un ajuar que los "bárbaros del sur" introdujeron en el Japón y que se empleó en los espacios católicos. En la parte superior derecha del Biombo namban de Freer Gallery of Art, Washington D.C., aparece una capilla u oratorio cuyo ingreso está flanqueado por unas cortinas bermejas." Asimismo, en el célebre Biombo namban del Kobe City Museum aparece una residencia jesuítica construida al estilo japonés donde, sin embargo, se puede observar el empleo de una cortina junto con el shoji o ventana de papel del piso superior. ${ }^{4)}$ De igual modo, la pintura La Virgen con las escenas de los quince misterios del Kyoto University Museum (Figura 2), aparecen pintadas las cortinas de brocado que abren la escena donde se representa la Virgen con el niño. Cabe subrayar que en la fuente figurativa de esta representación no se representan cortinas (Kamba 1998: 199), por lo que el citado elemento fue una añadidura del artista japonés.

Las cortinas que se colocaban junto con las imágenes sagradas tuvieron diferentes funciones dentro del contexto japonés. Por una parte, sirvieron para crear una escenografía litúrgica. Por la otra, se utilizaron para ocultar el altar como muestra el siguiente episodio ocurrido al comienzo de la misión franciscana en Japón, en el momento en que los frailes habían obtenido el permiso de establecer una iglesia en Kyoto pero no tenían aún licencia para predicar el evangelio:

...[el gobernador de Kyoto llamado Geni Hoin] embio luego a dezir a los 
frayles q cerrassen las puertas q salian a la calle y que por ningun modo admitiessen concurso de gente y que teniendo ellos necessidad de altar para si le cubriessen con cortinas, para q nadie le viesse y porque despues supo que no guardavan esto, se enojo tanto q yendo dos dellos a visitarle el primer dia de enero no los quiso ver y les embio a dezir que no cumplian lo que aian prometido de no publicar la ley de los christianos mas q los tornava a avisar q los havia de crucificar si no lo cumplissen (BRAH, Cortes, 9/2665, ff. 180v-181r).

Esta referencia indica que la autoridad japonesa, que no aceptaba enteramente la nueva fe traída por los misioneros, obligó a los mismos a hacer uso de cortinas para que su culto no quedara expuesto. En suma, las cortinas fueron un medio para prevenir una reacción contra la nueva religión.

Asimismo, para la ornamentación de las iglesias jesuíticas se emplearon telas y textiles de alta calidad. Al respecto, Organtino escribió lo siguiente en el año de 1577:

También se han hecho otras dos iglesias en la fortaleza de Sanga y Vocaxama agrandes y hermosas V.R. por amor de Dios busque algunas pieças de seda y brocado entre esos señores para hornamento destas iglesias, porq estos Japones son muy exteriores y vanos (BRAH, Cortes, 9/2663, ff. 144r-145v).

Acerca de la misma ornamentación de las iglesias referidas, un manuscrito del Archivum Romanum Societatis Iesu aclara que Organtino solicitó “...duas alcatifas grandes pera a altar e capella, alguns paramentos de brocado o de veludo con algunas imagenes formosas..." (ARSI, Jap. Sin. 8 I, f. 122v). Por lo que toca al uso de alfombras en el interior de la iglesia, el biombo namban que pertenece al señor Yashiro Nihei 矢代仁兵衛 de Kyoto (Figura 3) muestra un tapete colocado junto con el altar mayor sobre el piso cubierto de esteras de tatami. Para las alfombras, frontales, cortinas o paños que ornamentaban las iglesias jesuíticas debieron de utilizarse telas de "damasco", seda y terciopelo, ya que éstas circulaban dentro del ámbito jesuítico de Japón. 
Por lo que toca al término "damasco", cabe aclarar que en la documentación hispano-portuguesa este término se podía referir a textiles de distintas procedencias. Los "damascos" que los jesuitas obsequiaron a las autoridades japonesas debieron ser traídos de tierras lejanas como Europa o Medio Oriente (BRAH, Cortes, 9/2663, f. 62v). Sin embargo, una gran parte de los "damascos" que circulaban en Japón procedían de China, ya que ésta era un importante centro de dicha industria textil. Además, Japón importó estas producciones junto con otras hechuras, dado que las piezas artísticas procedentes de China fueron altamente estimadas, denominándolas como Kara mono (唐物). Así, el ajuar que utilizaba la élite japonesa estaba conformado por objetos chinos como muestra la siguiente noticia acerca del adorno usado en las fiestas de Nobunaga, en una plaza del monte Azuchi: se pusieron "muy ricos paños colgados, y muchas pieças de la China doradas y otras de damasco..." (BRAH, Cortes, 9/2663, f. 224v). Finalmente, el concepto de "damasco" podría también significar los textiles tradicionales de Japón, como muestra el siguiente dato: "En Meaco de arriba como V.R. sabe q es la corte de todo Japon avia hombres muy ricos donde se hazian todas las sedas y damascos que corren por todo Japon..." (BRAH, Cortes, 9/2663, f. $82 v)$. Los textiles identificados aquí como "damascos" se refieren a Nishijinori (西陣織) de Kyoto.

Por otro lado, en lo tocante al biombo perteneciente al señor Yashiro, es de notar lo que sus imágenes nos transmiten en relación al uso del espacio litúrgico. En él se ve que en el interior de la iglesia se encuentran sólo el padre y dos diáconos, mientras que los samurai y occidentales asistentes a la misa están sentados en la veranda que está protegida con un alero. En el caso de esta representación, pudo haberse optado por la solución de eliminar la presencia de las demás personas dentro de la habitación para dar mayor claridad a la escena de la misa. No obstante, en la práctica, la parte de veranda debió de servir para recibir a los concurrentes. Lo cierto es que el lugar donde se escuchaba la misa dependía de la posición social y del género de las personas. Asimismo, dentro del contexto japonés, distinguir el estatus y género del huesped y recibir a la persona según su estatus fueron importantes como el mismo Valignano aclara en sus instrucciones constructivas 
(Valignano 1946: 273, 281). Con respecto a esta cuestión, en el biombo de Kano Naizen (Figura 4) se representan cuatro concurrentes a la misa: en el interior de la iglesia, al lado derecho, se hallan dos samurai de alta jerarquía que llevan kataginu (肩衣), que es una chaqueta con aletas plegadas amplias que ostenta el emblema del clan al que pertenece el samurai, mientras que al lado izquierdo se encuentra un monje con una capucha; asimismo, un samurai sin kataginu, es decir, de menor categoría se encuentra representado en el área de la veranda.

También es oportuno advertir que cuando había mucha concurrencia, para dar mayor cabida a la iglesia, se "derribaban" los muros como indica la siguiente referencia sobre la iglesia de Goto: "Estava la yglesia toda llena de gente basta fuera de la capilla q la divide vn arco de papel bermejo y blanco y no cabiendo derribaron vna pared q es facil en Japon." (BRAH, Cortes, 9/2663, f. 426r) Aquí “derribar una pared" podría significar quitar fusuma, que son los paneles rectangulares de papel que delimitan un cuarto y sirven a la vez de puerta. Fusuma es un recurso tan versátil que permite crear un espacio de distintas dimensiones, ya sea dividiendo el interior o haciendo continuas distintas salas. Esta cita revela que esta tradición japonesa fue adaptada para ajustar las dimensiones del espacio litúrgico católico según la cantidad de los fieles que asistieran a la misa. Asimismo, con relación a la cita anterior, es de destacar que se mencione "vn arco de papel bermejo y blanco" que dividía la capilla, ya que el concepto de "arco" sugiere una ornamentación de estructura arquitectónica occidental. En este caso parece que se moldeó un arco utilizando los mismos materiales con los que se forma un fusuma, creando así un híbrido entre la tradición indígena y la europea.

En la parte más sagrada de la iglesia se hallaba el altar mayor. éste podría estar recubierto de laca con motivos ornamentales hechos con base en la técnica de maki-e como se observa en el biombo de Kano Naizen (Figura 4) o bien adornado con un frontal como muestra el biombo del señor Yashiro (Figura 3). Asimismo, en la obra de Naizan se observa cómo sobre el altar están colocadas piezas litúrgicas como candeleros y copones dorados. Por otra parte, la documentación prueba la presencia de cálices, custodias y relicarios de plata en las iglesias kirishitan (ARSI, Jap. Sin. 50, f. 30v). En el ajuar de las 
iglesias kirishitan se incluían también los incensarios, ya que la documentación japonesa indica el uso de un incienso llamado kuroyaki, que se refiere al incienso arábico (Marega 1942: 76; Gonoi 2005: 111, 113). En el centro del altar se colocaba la imagen devocional más importante. En las representaciones de los biombos namban, en esta parte central del altar mayor aparece el Salvator Mundi o la Virgen, que fueron los iconos que más circularon en el Japón junto con la santa faz o "Verónica" según indica la documentación japonesa y europea.

El ajuar de las iglesias japonesas debió de conformarse con objetos de variadas procedencias. Por una parte, se utilizaron piezas traídas desde Europa. En el caso de los ornamentos de la iglesia de Nuestra Señora de la Asunción en Kyoto se menciona: "La iglesia se adorno con vnos ricos ornamentos que el $\mathrm{P}^{\mathrm{e}}$ Visitador le traxo, y con sus candeleros de plata y incensarios y naveta con su retablo hermoso." (BRAH, Cortes, 9/2663, f. $273 v$ ) Asimismo, Fróis, en relación a la procesión celebrada durante la Semana Santa de 1581 en Takatsuki, describe lo siguiente:

Todos los caballeros llevavan en las manos sus imagines q $\mathrm{P}^{\mathrm{e}}$ Visitador avia traido, yvan tambien 25 niños xpianos con sus alvas y imagines, llevavan tambien vnas andas 4 caballeros muy aderezados y en lugar de vanderas yvan vnas imagines en lienzo al olio que $\mathrm{P}^{\mathrm{e}}$ avia traido y gran numero de linternas con mill invenciones que grandemente illustravan la fiesta. El $\mathrm{P}^{\mathrm{e}}$ Visitador llevava el lignum crucis debajo de vn palio rico y los padres las capas y dalmaticas (BRAH, Cortes, 9/2663, f. 224r).

Lo anterior muestra que Valignano trajo varias imágenes entre las cuales habían lienzos al óleo. Además, la indumentaria litúrgica occidental fue un elemento importante en los actos de culto. Todo parece indicar que su uso se difundió ampliamente, ya que dicha prenda sacerdotal no se registra sólo al nivel documental, ${ }^{5}$ sino también en las fuentes pictóricas. En efecto, en los biombos antes citados, se representa el sacerdote con su capa pluvial, mientras que los diáconos aparecen vestidos con albas. Asimismo, entre los objetos traídos por Hasekura Tsunenaga desde Europa en su misión diplomática 
realizada entre 1613 y 1620, se incluía una capa sacerdotal, hoy perteneciente al acervo del Sendai City Museum.

El envío de la delegación japonesa a Europa fue, sin duda, un acontecimiento que ayudó a enriquecer la cultura católica de Japón. En efecto, no sólo en la citada misión de Hasekura, sino también en la anterior misión de Tensho (1582-1590), se trajeron diversas hechuras como muestra la siguiente lista de objetos que el Sumo Pontífice concedería a los cuatro jóvenes embajadores enviados por los daimyo cristianos de Kyushu:

Que Su Sanctidad los arma caballeros de su propria mano diziendo Missa, cosa q rarissimas vezes suele hazer, dando a cada vna gruessa cadena de oro con vna medalla.

Dales tambien tres ternos riquissimos, q son todos los ornamentos de Sacerdote, Diacono, y Subdiacono, y tres capas de Asperge, y tres frontales de Brocado de mucho precio, para las tres provincias de Japon. Embia tambien $\mathrm{Su} \mathrm{S}^{\text {ad }}$ a aquellos tres reyes tres presentes de grande estima, q son, el esto que se bendize la noche de Navidad, q no le suelen embiar sino al Emperador o Reyes, y la Rosa de oro q se bendize la Dominica, letare, y el capelo o sombrero q se bendize el mesmo dia.

Embia tambien al Rey Don Bartholome vna cruz toda de oro con vn poco del lignum crucis, con vn Breve Apostolico por el qual le junta con los demas Reyes Xpianos para q en consistorio pueda tener su lugar diputado entre los Reyes (BRAH, Cortes, 9/2663, f. 413r-413v).

Con relación a los objetos traídos por dichos cuatro jóvenes embajadores, Fróis registra en la carta annuae de 1590 la siguiente información de la tierra de Arima:

...Gran plazer tienen los japones de ver, y oir tocar tanta variedad de instrumentos musicos como han traido de Europa estos señores, y estan admirados de su melodia, y espantados la armonia y consonancia de tantos instrumentos juntamente concertados, y confiessa que es $\mathrm{n}^{\text {ra }}$ musica muy mas dulce y mas suave de lo que ellos primero dezian (BRAH, 
Cortes, 9/2663, f. 461v).

Asimismo, un día después de esta presentación musical, el Visitador bendijo el nuevo palacio de "Don Protasio" (Arima Harunobu) "Teniendo vestido vn pluvial (o capa) que su Santidad enbio al Japon" (BRAH, Cortes, 9/2663, f. 462r).

Mas, en paralelo a la introducción y uso de objetos europeos se dio una adaptación en el ajuar eclesiástico. Fróis, por ejemplo, advierte que mientras "nuestras imágenes se pinta en madera, ellos las suyas en papel", y mientras los occidentales estiman mucho las pinturas al óleo, éstas son desconocidas en el Japón, donde "vale muchos cruzados una figura en tinta negra" (López 1970: 29-30). La tradición indígena pictórica de sumi-e fue aprovechada para el ajuar del espacio litúrgico kirishitan, ya que desde el comienzo los cristianos pintaban el crucifijo o la cruz "con tinta y en papel" (Ibid.: 30). Incluso, en las tierras de Don Bartolomé (Omura Sumitada), una cruz pintada de manera improvisada ofició un milagro, por lo que esta obra en papel fue colocada en el lugar del retablo (BRAH, Cortes, 9/2663, f. 308v).

Asimismo, es importante advertir que los motivos ornamentales de la pintura chino-japonesa también formaron parte de la ornamentación católica de Japón. Por ejemplo, en la obra de Kano Naizen (Figura 4), al fondo de la escena de la misa se aprecia un biombo o mampara que ostenta un paisaje en tinta. De igual modo, el género de pintura de flores y pájaros fue adaptado para la ornamentación litúrgica como indica la siguiente anécdota:

...en la celebración del primer aniversario de la muerte de una cristiana de Osaka, la iglesia estaba adornada por oficiales japoneses bajo la dirección del hermano Juan Torres de Yamaguchi, con papeles que cubrían el techo y las paredes en los que estaban pintados trabajos de diversas flores y pájaros (Fernão Guerreiro, citado por López 1970: 30).

El respeto hacia las tradiciones pictóricas locales se manifestó también en la enseñanza artística de la Compañía de Jesús. En efecto, en el seminario de Hachirao, en la península de Shimabara, no sólo se enseñaron las técnicas de 
pintura al óleo y láminas de cobre para hacer estampas sino que los ejercicios de los aprendices también incluían hacer figuras en aguada o tinta (BRAH, Cortes, 9/2665, f. 10r). Luís de Cerqueira, S.J. (1552-1614), por su parte, apuntó en 1603:

...Otros aprenden a pintar \& a abrir laminas $\mathrm{p}^{\mathrm{a}}$ imagems de matrises, assi dos caracteres de Japão, como de nosa letra, com q se da muy grande aiuda a esta christandade. Porq achei as igreijas bem puidas [proveídas] de imagems de oleos \& de tintas de agoada q fazem muy boas, por aver entre elles algums mui boms pintores, $\&$ repartese pollos $\mathrm{p}^{\text {es }}$ grande quantidade de imagens de tintas, \& de estampa, con $\mathrm{q}$ se desperta $\mathrm{m}^{\text {to }} \mathrm{a}$ devoção destes xpãos (BRAH, Cortes, 9/2665, f. 38v).

Esta referencia muestra cómo se llevaba a cabo el aprendizaje de pintura en un taller de la misión jesuítica, en el que se incluía la producción de láminas para imágenes impresas y la práctica de la tipografía japonesa y europea. Además, las iglesias estaban bien proveídas de imágenes hechas con óleos y tintas de acuarela, dado que entre ellos se encuentran muy buenos pintores y se reparten gran cantidad de imágenes de tintas y estampas.

El aprovechamiento de las tradiciones pictóricas japonesas y europeas dio como fruto obras singulares como muestran los ejemplos de San Francisco Xavier de Kobe City Museum y La Virgen con las escenas de los quince misterios de Kyoto University Museum (Figura 2). En estas pinturas se emplearon materiales locales. Mas, por lo que atañe a las técnicas, se aplicaron tanto técnicas occidentales como nativas. Así, la segunda obra fue realizada al temple sobre papel de bambú (Takeda 2002: 54-55) y luego puesta sobre el soporte vertical llamado kakemono, rollo colgante de formato vertical utilizado para la pintura y caligrafía japonesa. Los trazos negros que delinean el contorno de las figuras presentan similitudes con los de la caligrafía (Ibid.: 54). Pero por otra parte, de acuerdo con las tradiciones occidentales, el autor trató de dar volúmenes a las figuras humanas mediante el uso de sombras, así como de crear una ilusión de profundidad en la superficie pictórica aplicando la perspectiva lineal. 
Tradicionalmente en la pintura japonesa no había costumbre de dar realismo a las representaciones humanas con base en volúmenes creados mediante el claroscuro o respetando las proporciones naturales del cuerpo humano. Asimismo, existía una tradición para plasmar la profundidad en la superficie pictórica pero esta perspectiva se conseguía de forma espontánea sin basarse en las reglas matemáticas ni ciencias ópticas. Por lo tanto, asimilar las novedades de la tradición artística europea se convirtió en reto para los pintores japoneses del llamado "siglo Kirishitan".

Cabe señalar que la ornamentación interior de las iglesias japonesas se caracterizaron por su esplendor. Así, Rodrigues Giram escribió lo siguiente acerca de la nueva iglesia de Kyoto edificada en 1605:

...[a nova igleja] se le acabou de perfeiçoar de todo pintandose e dourandose o ferro da capella mor ao modo de Europa, e sobretudo ornandose os altares com $m^{\text {to }}$ [muito] bons retabolos de oleos pintura pera os japoens $m^{\text {to }}$ nova e nunca vista e de q grandem $^{\text {te }}$ pasmaõ, tanto $q$ muitos ou quasi todos julgam as imagens dos retabolos por estatuas de vulto, polla perfeição dellas, por não aver em Japão tal modo de pintar com sombras. Como a igleja sahio tam capaz $q$ som $^{\text {te }}$ no corpo, tirando o cruzeiro, caberão duas mil pessoas, há de ordinário aos domingos e festas grande concurso dos christãos, $q$ com $g r^{\text {de }}$ fervor e devocam vem a igreja movidos tambem da commodidade e decencia... (ARSI, Jap. Sin. 55 , f. 348r)

Estas descripciones transmiten que la iglesia en cuestión fue concebida en gran medida a la manera occidental. En efecto, la planta arquitectónica contaba con crucero y la decoración interior se realizó "ao modo de Europa". La capilla mayor tenía "ferro" (hierro) dorado, que puede referirse a la reja que delimitaba el presbiterio; asimismo, había altares que ostentaban retablos de pintura al óleo. Con relación a estas hechuras, cabe subrayar el comentario de que los nativos confundían dichas imágenes con estatuas de bulto debido al realismo conseguido a base de la técnica de sombras. En lo tocante a los retablos, Rodrigues Giram proporcionó datos más minuciosos: 
...o novo retábolo da Ascensão de Christo Nosso Senhor, com os Apóstolos em baixo, obra muy prima e bem acabada, com sua guarnição de colunnas e tudo o mais ao modo de Europa, o qual retábolo anche toda a altura da Capella, q em tal dia [A pascoa da Resurreicão] se armou de boas pecas de seda lustrosam ${ }^{\text {te }}$ : pollo que assi pera verem a nova e fermosa imagen como tamben a armacam da igreja concorreo tanta gente q era necess ${ }^{\circ}$ fazer tornar por força a os q ja tinhão visto pera dar lugar a outros q de novo vinhã̃ a ver. [...] ... Em hum dos altares da nova igreja está hum retábolo em que está pintado o aparecimento de Christo Nosso Senhor a Nosso B. padre Ignácio quando lhe disse «Ego vobis Romae propitius ero»... (ARSI, Jap. Sin. 55, ff. 348r-348v, 353r)

Aquí se registran al menos dos retablos: uno de La ascensión y el otro de $L a$ aparición de Jesucristo a Ignacio Loyola. En cuanto al primer retablo, ocupaba toda la altura de la capilla, la cual se adornó de buenas piezas de seda lustrosa durante la Pascua de Resurrección. Asimismo, Rodrigues Giram ofrece otra descripción de la misma iglesia de Kyoto pero en ocasión de la Pascua de Navidad:

Tinha-se tambem acabado a nova igreja do Meaco este Natal paszado feita com as esmollas que $p^{a}$ isso derã̃ os christaõs; a quel posto q na grandeza e sumptuosidade não tenha comparaçam com alguns templos principaes de idolos, $q$ ha no dito Miaco e seu contorno, todavia por ser feita no nosso modo, e ter os retabolos de boas pinturas de oleo, de q os Japoes pasamam, lhes agrada $m^{\text {to }}$ a maravilha: o $q$ tudo ajudva $p^{a}$ mais solennizar o dito enterram ${ }^{\text {to }}$ segundo o desejo e promessa de Qiôgoku Maria (ARSI, Jap. Sin. 55, f. 298r).

La referencia: “...na grandeza e sumptuosidade não tenha comparaçam com alguns templos principaes de idolos...” denota la rivalidad que los misioneros sentían con respecto a las obras de los templos nativos. Precisamente con la finalidad de hacer distinguir el espacio del culto católico de los templos budistas y sintoístas ellos optaron por hacer obras "no nosso modo", además 
de que ello daba un efecto positivo para solemnizar al rito católico.

\section{Consideraciones finales}

La característica por excelencia de los espacios de culto católico del Japón moderno temprano fue el de ser efímeros. Su ornamentación litúrgicadevocional estuvo en constante movimiento debido a diferentes circunstancias locales: las perturbaciones de la sociedad local, persecuciones cristianas y la necesidad de realizar predicaciones itinerantes. A diferencia de las obras arquitectónicas que se apoyaron en los materiales y técnicas constructivas locales a lo largo de todo un siglo de evangelización, fue en el ajuar interior donde se manifestó en mayor medida la aculturalidad. Así, los misioneros introdujeron imágenes europeas, tapices y cortinas y piezas litúrgicas como candeleros, copones, calices y custodias de plata.

Para los misioneros, crear un espacio distinto y novedoso para los fieles nativos fue de gran importancia para reforzar la identidad católica. Por ello, las fuentes transmiten la inquietud por parte de los religiosos europeos de acomodar el ajuar "a modo de iglesia" o "a modo de Europa" o "no nosso modo". Para ello, las piezas traídas desde distintas partes del mundo, así como las obras católicas japonesas que se alimentaban de diversas tradiciones jugaron un papel decisivo para diferenciarse de las religiones nativas y demostrar su presencia y poder en el contexto local. Mas, la integración de objetos "extraños" conformó un espacio litúrgico muy dintinto al de Europa. En ese sentido, los conceptos documentales de adornar "a modo de iglesia" o "a modo de Europa" fueron relativos y sugerían, en la práctica, un espacio cosmopolita pero a la vez indigenizado manifestando el sello propio de la Iglesia japonesa. 


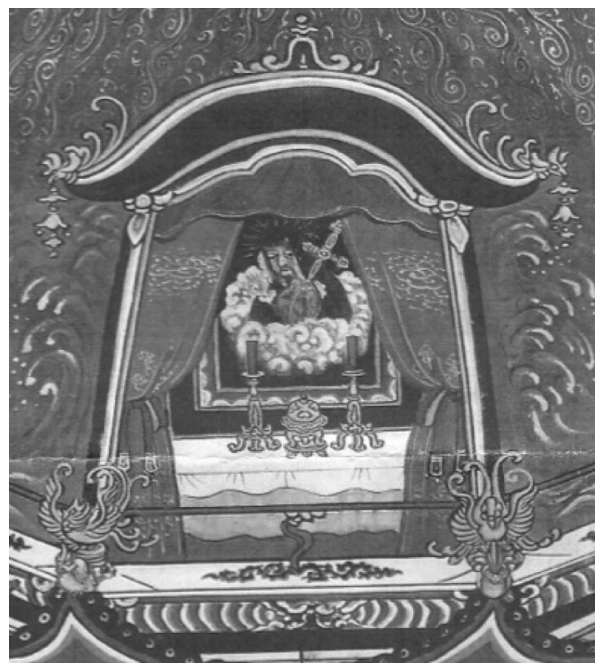

Figura 1: Capilla con cortinas flanqueadas, detalle del Biombo namban de Kano Naizen, finales del siglo XVI-principios del XVII. Tomada de Okamoto y Takamisawa, Namban byobu, 1970. Colección de Kobe City Museum

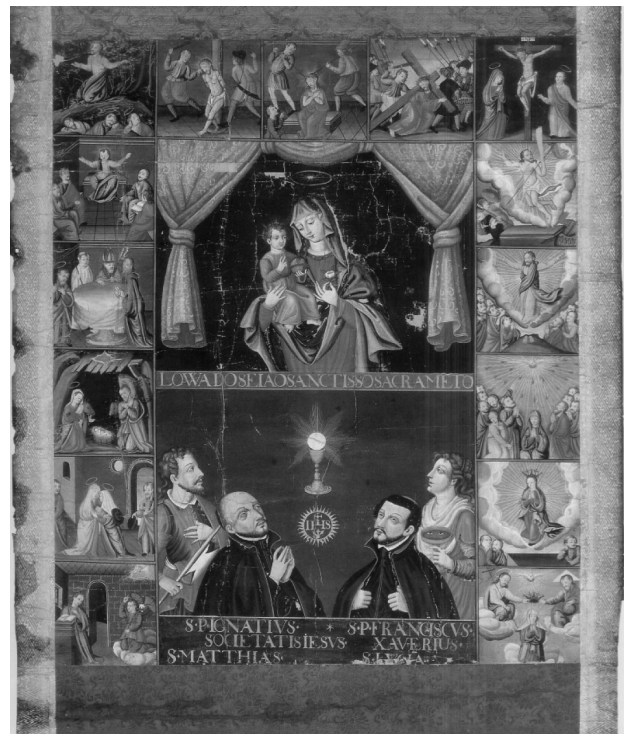

Figura 2: Anónimo, La Virgen con escenas de los quince misterios, siglo XVII. Colección de Kyoto University Museum 


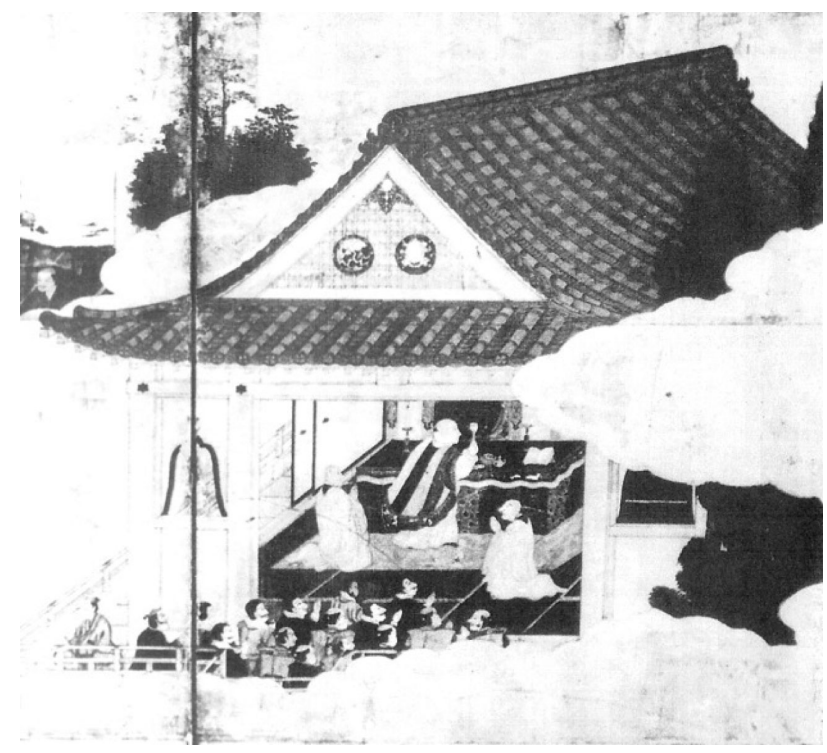

Figura 3: Anónimo, Biombo namban, detalle, siglo XVI-XVII. Tomada de Okamoto y Takamisawa, op. cit. Colección del señor Yashiro Nihei

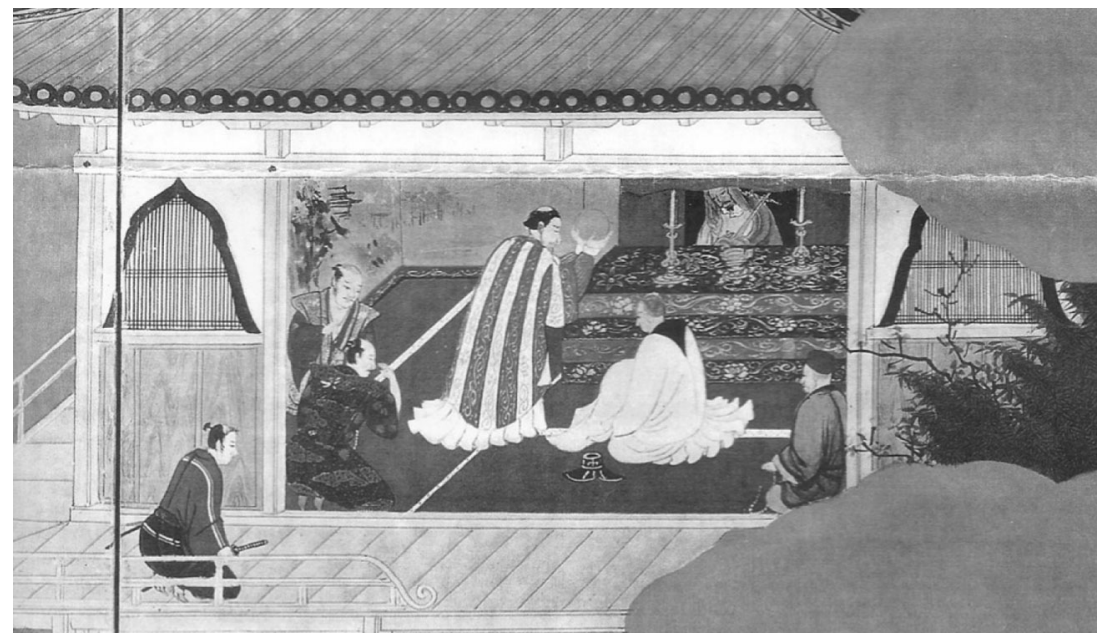

Figura 4: KanoNaizen, Biombo Namban, detalle, finales del siglo XVI-principios del XVII. Tomada de Okamoto y Takamisawa, op. cit. Colección de Kobe City Museum 


\section{Notas}

1) En el caso del virreinato novohispano, desde antes de la secularización de los bienes eclesiásticos hubo costumbre de trasladar y reciclar no sólo las imágenes y piezas sueltas, sino también las obras de dimensiones grandes como los retablos. Como ejemplo del traslado y reutilización de los retablos, cabe mencionar el actual retablo mayor del templo franciscano de Cuauhtinchán, en el estado de Puebla, México. Cf. Efraín Castro Morales, "El retablo de Cuauhtinchán, Puebla", Historia Mexicana, vol. XVIII, núm. 2 (70), oct.-dic. 1968, pp. 179-189.

2) Por lo que se refiere a la "piedra del ara", se trata de la piedra consagrada que era colocada en el altar mayor, sobre la que el sacerdote dice la misa (Lisón 2004: 108), aunque en la documentación portuguesa de los siglos XVI y XVII, "a pedra de ara" se emplea en sentido amplio, ya que es una forma común de llamar al altar mayor.

3) http://www.learner.org/courses/globalart/work/166/zoom.html (día de consulta: 13 enero 2012)

4) http://www.city.kobe.lg.jp/culture/culture/institution/museum/meihin/elements /046-1-1.jpg (día de consulta: 3 febrero 2012)

5) El uso de la indumentaria litúrgica occidental se registra no sólo en la documentación europea, sino también en la japonesa. Véase Tachihara Suiken, Kirishitan hofuku shokibutsu mokuroku ryakuzu [1800], edición facsimilar, Osaka, Osaka Mainichi Shimbunsha, 1928.

\section{Fuentes inéditas}

\section{Archivum Romanum Societatis Iesu: ARSI}

Jap. Sin. 8 I, ff. 122v-123r, una carta de Organtino dirigida a Valignano, Kyoto, 21 sep. 1577.

Jap. Sin. 50, ff. 19r-42r, Luís Fróis, “Annuae”, Bungo, 6 junio 1577.

Jap. Sin. 55, ff. 291r-362r, João Rodrigues Giram, “Annuae Iapon de Outubro do anno de 1605 ate o mesmo do anno de 1606, pera N. R ${ }^{\text {do }} \mathrm{P}^{\mathrm{e}}$ Geral Claudio Aquaviva", Nagasaki, 15 feb. 1607.

\section{Biblioteca de la Real Academia de la Historia, Madrid: BRAH}

Cortes, 9/2663, ff. 2r-9v, una carta de Alexandro Valerregio, Goto, Nagasaki, 1570.

Cortes, 9/2663, ff. 40r-51r, una carta de Luís Fróis dirigida a Francisco Cabral, Kyoto, 20 abril 1573.

Cortes, 9/2663, ff. 52r-74v, una carta de Francisco Cabral dirigida al provincial de la 
India Antonio de Quadros, Nagasaki, 23 sep. 1572.

Cortes, 9/2663, ff. 77r-91v, una carta de Luís Fróis dirigida a Francisco Cabral, Kyoto, 17 junio 1573.

Cortes, 9/2663, ff. 132r-143v, una carta de Luís Fróis, Japón, 6 junio 1577.

Cortes, 9/2663, ff. 144r-145v (numeración antigua: ff. 175r-176v), una carta de Organtino dirigida a Valignano, Kyoto, 20 sep. 1577.

Cortes, 9/2663, ff. 222v-226r, una carta de Luís Fróis dirigida al padre rector de Bungo, Kyoto, 14 abril 1581.

Cortes, 9/2663, ff. 297r-316v, "Relacion de algunas cosas notables q en estos vltimos años de 82, 83, 84, han acontecido en los reynos de Japon sacada de las vltimas cartas que los $\mathrm{P}^{\text {es }}$ de la Compañía q alla andan escrivieron al $\mathrm{P}^{\mathrm{e}}$ General y llegaron este año de lo ochenta y cinco en el galeón de Malaca”.

Cortes, 9/2663, ff. 397r-406r, una carta annua de Japón de Damian Marín para el padre general en Roma, en 1584.

Cortes, 9/2663, ff. 413r-413v, una carta de Benito López dirigida a Gil González Provincial de Andalucía, enviada de Roma, 20 mayo 1585.

Cortes, 9/2663, ff. 458r-482r, Luís Fróis, una carta annua del Japón del año de 1590, Nagasaki, 12 oct. 1590.

Cortes, 9/2665, ff. 1r-18r, Pedro Gómez, Annua del Japón, Nagasaki, 15 marzo 1594.

Cortes, 9/2665, f. 38v, Luis de Cerqueira, Nagasaki, 12 enero 1603.

Cortes, 9/2665, ff. 179r-182r, sumario de una relación que el provincial de san Francisco embió desde las Filipinas

Jesuitas, leg. 9/7238, "Segunda parte Da historia Eclesiastica de Iapam, na qual se contem como se deu principio a pregaçam do sagrado Evangelho nã quelle reyno de Iapam pello Sancto pe Francisco Xavier, e progresso q teve aquel christãndade do anno de 1549 ate o de 1552 em q o Sancto pe Franco Xavier passou desta vida”, escrita em Lisboa a 16 março de 1556. Mandou Logo Franco Barreto tirar estas inquicições em Goa, Becajam, CocSim, no cabo de Comorj, e Malaca.

\section{Bibliografía}

Gonoi, Takashi 五野井隆史, “The Devotional Instruments of the Christian Missionaries. Part I キリスト教布教とキリシタンの道具 (1)”, Research Institute of Christian Culture Bulletin キリスト教文化研究所紀要, vol. 20, no. 1, 2005, pp. 98-120.

Hidaka, Kaori 日高薰, Ikoku no hyosho: kinsei yushutsu shikki no sozoryoku 異国の表 象：近世輸出漆器の創造力, Tokyo, Brüche, 2008. 
Impey, Oliver y Christiaan Jörg, Japanese Export Lacquer 1580-1850, Amsterdam, Hotei, 2005.

Kamba, Nobuyuki 神庭信幸 et al., "Research on the "Painting of the Madonna with the Infant Jesus and her Fifteen Mysteries” owned by Kyoto University 京都大学 所蔵「マリア十五玄義図」の調査”, Bulletin of the National Museum of Japanese History 国立歴史民俗博物館研究報告, vol. 76, 1998, pp. 175-210.

Lisón Tolosana, Carmelo, Antropología cultural de Galicia, Madrid, Akal, 2004.

López Gay, Jesús, S.J., La liturgia en la misión del Japón del siglo XVI, Roma, Typis Pontificae Universitatis Gregorianae, 1970.

Marega, Mario, Bungo kirishitan shiryo 豊後切支丹史料, Beppu, Salesio-kai, 1942.

Martínez, Domingo, Compendio histórico de la apostólica provincia de San Gregorio de Philipinas de religiosos menores descalzos de N.p. San Francisco, en que se declaran sus heroycas empressas, para la dilatación de nuestra santa fé por varios reynos, y provincias del Assia: con las vidas, martyrios, y hechos en comun, y en particular de sus venerables hijos, correspondientes a la sucesión de los trienios, missiones, desde su fundación, hasta los años del Señor de mil setecientos y ocho, Madrid, viuda de Manuel Fernández y del Supremo Consejo de la Inquisición, 1756.

Okamoto, Yoshitomo 岡本良知 y Tadao Takamisawa 高見沢忠雄, Namban byobu 南 蛮屏風, 2 vols., Tokyo, Kajima shuppankai 鹿島出版会, 1970.

Takeda, Eri 武田恵理, “A Copy of the Fifteen Mystery of St. Mary in the Collection of Kyoto University and the Study of its Painting Technique 京都大学総合博物館蔵 重要文化財「紙本著色聖母子十五立義図 ·聖体秘跡図」の再現模写と描画技 法の研究”, tesis doctoral en Conservación y Restauración, Tokyo, Tokyo National University of Fine Arts \& Music, 2002.

"Taketa-shi no Santiago no Kane. Hatsu no seibun bunseki: kokunai de chuzo ka 竹田 市のサンチャゴの鐘 初の成分分析：国内で鋳造か”, Oita godo shimbun 大分 合同新聞, 4 de junio de 2012, edición matutina, p. 21.

Valignano, Alessandro [Alexandro], S.J., Il cerimoniale per i missionari del Giappone, ed. y notas de J.F. Schütte, S.J., Roma, Edizioni di "Storia e letterature", 1946.

Yamazaki, Tsuyoshi 山崎剛, Umi wo watatta nihon shikki I (16-17 seiki) 海を渡った 日本漆器 I (16-17世紀), Tokyo, Shibundo 至文堂, 2001 (Nihon no bijutsu, 426). 
$<$ Resumen $>$

\title{
El ajuar de las iglesias kirishitan: interculturalidad y construcción de una identidad cristiana
}

\author{
Rie ARIMURA
}

Las transferencias artísticas, culturales y científicas en tres océanos promovidas por las monarquías ibéricas y la Iglesia católica en la primera era de globalización, se investigan hoy a partir de complejos procesos de intercambios y de los aportes de distintas regiones del orbe. Esta nueva interpretación ha venido a substituir el viejo paradigma que veía en estos fenómenos el sello de una simple y rápida expansión de la civilización europea o una interacción bilateral entre el mundo ibérico y una determinada sociedad.

En el marco de esta revisión, el presente trabajo corrobora documentalmente la interculturalidad del ajuar litúrgico de las iglesias japonesas del llamado "siglo Kirishitan" (1549-1639). Las fuentes hispano-portuguesas muestran la introducción, uso y traslados de diversas clases de ornamentación católica en el contexto japonés. Para los misioneros, crear un espacio distinto y novedoso para los nativos fue de gran importancia con el fin de reforzar su identidad católica. Así, los documentos transmiten la inquietud por parte de los religiosos europeos de acomodar el ajuar "a modo de iglesia" o "a modo de Europa" o "no nosso modo". Para ello, las piezas traídas desde distintas partes del mundo Europa, América, Medio Oriente, Filipinas y China, jugaron un papel decisivo. Debido a esta característica cosmopolita, el ajuar litúrgicodevocional de las iglesias kirishitan debió ser muy distinto al de Europa. En ese sentido, el reto de acomodar el espacio "a modo de iglesia" o "a modo de Europa" fue relativo y sugería, en la práctica, un singular espacio católico manifestando el sello propio de la Iglesia japonesa. 